DOI 10.37882/2500-3682.2021.12.12

\title{
БАЗОВЫЕ ЦЕННОСТИ В СИМВОЛИЧЕСКОМ ПОЛЕ ДУХОВНОЙ КУЛЬТУРЫ РОССИИ
}

\section{BASIC VALUES IN THE SYMBOLIC FIELD OF SPIRITUAL CULTURE OF RUSSIA}

N. Kovalenko

Summary: This work is devoted to the basic spiritual values in the symbolic field of Russian culture, expressing the content of the domestic cultural code. The author actively uses methodological means of comprehending it, which are contained in the philosophical heritage of cultural figures of the «Silver Age»: A.F. Loseva, N.A. Berdyaeva and others. The Slavophil category of collegiality is viewed as a reflection of the essence of the spiritual world of the Russian person.

Keywords: values, basic values, spirituality, spiritual culture, collegiality.

\author{
Коваленко Наталья Геннадьевна \\ к.ф.н., доцент, Санкт-Петербургский государственный \\ аграрный университет \\ nataly6707@mail.ru
}

Аннотация: Данная работа посвящена базовым духовным ценностям в символическом поле культуры России, выражающими содержание отечественного культурного кода. Автором активно используются методологические средства его постижения, которые содержатся в философском наследии деятелей культуры «серебряного века»: А.Ф. Лосева, Н.А. Бердяева и др. Славянофильская категория соборности рассматривается как отражение сущности духовного мира русского человека.

Ключевые слова: ценности, базовые ценности, духовность, духовная культура, соборность.

Сегодня, как пишет белорусский философ В.Л. Абушенко, под ценностями необходимо понимать смыслообразующие основания бытия индивида, устанавливающие направление и мотивации жизни человека, а также задающие деятельность и определенные деяния, поступки [3; С.25]. А аксиология как философская наука сформировалась из потребности осознания неоднородности научного знания, которое конституируется в том числе и из знания социогуманитарного и культурологического. Согласно аксиологическому подходу, ценности можно подразделять на «инструментальные» и «терминальные». Основой этих классов ценностей служит представление о ценностях - средствах и ценностях высших, базовых, которые являются целями сами по себе. (добро, счастье, свобода).

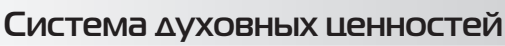

Базовые ценности духовной жизни человека обладают принципиально неинструментальным и неутилитарным характером. Они являются базовыми, поскольку ценности, которые положены в основу выбора потребностей и возможных средств их получения, достигаются субъектом в конкретных условиях. Комплекс, сочетание и характер изменения таких ценностей в каждом отдельно взятом случае будут разнообразными. Однако при этом в их базу будут заложены ценности, на которые непосредственно и нацелена деятельность человека. А проблема деятельности, как мы отмечаем, ещё со времён Аристотеля придаёт научный характер осознанию и исследованию ценностей. При осуществлении человеческой деятельности наблюдается присутствие универсального аспекта. Последний проявляется в нацеленности на до- 
стижения благ и счастья. Все существующие формы реализации подобного рода ценностей также обладают универсальными аспектами, которые проявляются, прежде всего, в модернизации, коммуникации и потреблении. Данные виды деятельности нацелены на такие ценности как польза, богатство, благополучие и т.д.

Любой вид жизнедеятельности обладает двояким обеспечением - идеальным (от субъекта) и материальным (объективные условия). Что относится к идеальной деятельности, то она может рассматриваться в качестве познания, понимания и проектирования, которые направлены на такие ценности как истина, правда и т.д. Также в основу идеальной деятельности положен ряд и универсальных видов деятельности. Последние при этом обуславливают её целостность. Отмеченные виды деятельности основываются на ценностях мудрости и рефлексивного обоснования. Сложность отмеченной проблематики заключается в том, что ни этот список, ни экспликация его элементов, не могут претендовать на необходимую полноту и высокий уровень достоверности. Но, если сравнивать предлагаемую классификацию с другими существующими на данный момент, то она более системна [4; С.131-140].

При рассмотрении характеризующих качеств психологической готовности к выполнению какой-либо формы деятельности, исследователи подчеркивают необходимость учета особенностей той или иной формы деятельности (С.С. Гриншпун, Е.А. Климов, Н.И. Крылов, А.И. Подольский, В.В. Сериков др.). Поэтому готовность человека к практической реализации духовных ценностей, деятельности идеально-значимого характера как необходимое качество личности. Человек духовный это тот, кто успешно использует нравственные ценности в ежедневной жизни. Отмеченная готовность к деятельности нами анализируется в рамках следующих составляющих: интеллектуальной, мотивационной и операционально-деятельностной [5].

Интеллектуальный компонент готовности личности к принятию и выполнению духовных ценностей показывает информированность о духовной стороне жизнедеятельности, включающий в себя:

- знание основных духовных ценностей;

- понимание духовных ценностей как основы ежедневной жизнедеятельности;

- понимание необходимости действия посредством духовных принципов в жизненных ситуациях.

- составе мотивационного компонента готовности к реализации духовных ценностей личности выделяют два принципа:

- позитивное отношение к использованию в ежедневной жизни духовных ценностей;

- поддержание духовых ценностей как смыслообразующих в жизни человека.
Операционально-деятельностный компонент приобретает четко выраженный духовный контекст и характеризуется качеством знаний, умений и навыков в решении жизненных ситуаций: это относится к умению отметить духовный компонент ситуации; к умению использовать духовные принципы в изучении ситуации; к способности человека делать правильный выбор соответствующих духовных принципов и поведения. Проблема выбора в жизненных ситуациях на основе основополагающих духовных ценностей (добро, свобода, справедливость) стала ведущей в такой форме философии XX столетия как экзистенциализм (Ж.П. Сартр, А. Камю и др.) [6] Парадоксальное утверждение французских экзистенциалистов о том, что французы как нация были наиболее свободны в дни немецкой оккупации основывалось ими на том, что тогда для каждого француза был выбор: на чьей стороне - сопротивления или фашистских оккупантов. И это решение, этот выбор должен быть сразу и немедленно. А он основывался на том - на чьей стороне - на стороне добра (сопротивления), на стороне зла (оккупанты).

Выбор для экзистенциализма стал критерием, который обуславливает достижение духовных взглядов и системы нравственных знаний, обеспечивающих самостоятельную деятельность человека. Он связан с мотивационным критерием, который предусматривает отношение к придерживанию в каждодневной жизни духовных-нравственных ценностей против проявления бездуховности. А деятельностный критерий при этом включает в себя практическое использование человеком духовных знаний, умений и навыков. Их показатели - регулярность, уровень волевых действий, порядок в использовании духовных норм в поведении и др.

Система духовных ценностей, способ их применения в жизнедеятельности человека, осознание себя человеком духовным связано с воспитанием духовности. Это воспитание человека духовного складывается на базе общих принципов:

- адекватное восприятие правды;

- самовосприятие и восприятие других по культуре и религии, то есть толерантность;

- выражение интереса к другим людям;

- восприятие мира в его постоянном изменении и трансформациях.

Духовность человека лежит на милосердии к другим людям, отзывчивости, чувственности, терпеливости, вежливости и уважительности. Одной из наиболее высших ценностей в этом плане лежит ценность альтруизма как способности к самопожертвованию во имя других людей, своей страны, своего Отечества. Пример массового героизма советских воинов в годы Великой Отечественной войны - навсегда в нашей памяти [7; C.89-91].

Посредством духовных ценностей формируется 
смысл индивидуального бытия, указывая человеку на его место и определяя его главное предназначение. Для соблюдения логики и законов социокультурного развития, современный человек руководствуется больше должным, нежели существующим. Поэтому, данное разделение должного и существующего стало ключевой причиной появления и развития философии ценностей. Представленность ценностей в сознании индивида представляет собой некое разворачивание символа. В соответствии с данным символом, духовная ценность является ничем иным, как оригинальной «порождающей моделью». Именно это делает ее содержательно и эмоционально неограниченной [8].

Стремление связать развитие общества с духовной зрелостью человека присуще всем историческим периодам. Историческое развитие человечества неоднократно показывало, что религиозные верования могут быть как стабилизирующим фактором духовной среды и развития социума, так и поводом к общественным неустройствам (религиозные войны). Однако в любом случае наличие религиозной веры является фактором привития человеческому уму, массовому сознанию моральных и юридических критериев, которые чрезвычайно важны для жизни общества в целом. Цель любого воспитания состоит в формировании человека духовного. Нравственная жизнь человека связана с его нравственным воспитанием, потому что нравственное воспитание один из непрерывных процессов, обеспечивающих развитие человека как личности. Люди с положительными качествами, то есть люди-личности влияют на общество, ускоряют его развитие. Человек как личность не случаен в земном мире. По словам великого тюркского мыслителя и поэта Алишера Навои, человек приходит в мир, чтобы достичь совершенства. А путь к совершенству означает прямой путь к духовности. Во всех религиозных учениях Истина понимается как символ совершенства. Совершенство человека - это его стремление к Истине.

Совершенство имеет свои социальные критерии для каждого социального и культурно-исторического периода. Это потому, что люди различаются по умственным, духовным и физическим способностям, талантам и потенциалу. Действительно, нравственное воспитание ведет человека и народ к совершенству. Существует ряд инструментов, которые формируют и укрепляют нравственное воспитание. Они неразрывно связаны с научными и мировоззренческими устоями. Важнейшими из этих инструментов нравственного воспитания являются традиционные национальные (этнические) культурные ценности. Для русского человека - это ценности взаимной помощи и поддержки, социальной и православной идентификации, солидарности и соборности.

Вся история духовности показывает, что цивилизация - это продукт самосознания человека, его борьбы за торжество и развитие ценностей культуры. Свой огромный вклад в развитие отечественной духовной культуры внёс философ-экзистенциалист Николай Александрович Бердяев. Его концепция о совершенном человеке служит основой для обоснования философии совершенного человека в русской национальной идее. Она всецело поддерживается современным российским государством, которое формирует целевые программы по патриотическому и гражданскому воспитанию молодёжи [9].

Условия воспитания высокой духовности и совершенства, по Бердяеву, складываются из следующих факторов:

1. Концепция духовного очищения - одно из основных и фундаментальных условий совершенства.

2. Величие сердца принадлежит только совершенному человеку.

3. Концепция чистоты совести и совестливости выражается в форме единства языка и действия. Она, согласно учению Бердяева [10], способна противостоять социальным неустройствам в виде нигилизма, а сегодня - экстремизма.

В философии Бердяева своё место занимает символическая парадигма объяснения мира. По его словам, человек - самая маленькая часть Вселенной. Человек должен понять это и обязан очистить свою душу. Человек - олицетворение мира молого. По Бердяеву Вселенная состоит из имен сущностей и атрибутов, проявлений сущности. Сумма сущностей и атрибутов и есть Вселенная. Она состоит из двух частей: первая часть называется невидимым миром, а вторая часть называется видимым миром. Эти два мира называются разными именами в количественных и универсальных терминах. Например, мир творения и мир команд, мир собственности и мир ангелов, мир тела и души, мир восприятия и мир сознания, мир света и мир тьмы и так далее. Эти имена относятся к обоим мирам. Бердяев называет маленького человека и малую вселенную миром видимым, земным, наполненным природными явлениями и фактами человеческой культуры.

Для А.Ф. Лосева как философа культуры серебряного века символизм проявляется в отношении понимания человека. По Лосеву есть две вещи как знаки совершенства. Первое - мораль, другое - самопознание. В зависимости от того, существуют эти две вещи или нет, он разделил людей на три группы [11].

Первый - это люди, не приукрашенные моральными качествами и не знающие себя.

Во-вторых, люди, наделенные моральными качествами, но не знающие себя.

В-третьих, это люди, обладающие моральными каче- 
ствами и обладающие самосознанием.

Следовательно, совершенство человека достигается через нравственность и самопознание.

В философии Лосева был разработан уникальный этический кодекс идеального человека. Обладание качествами нравственности и самопознания считается мечтой каждого человека. Идеальный человек - это, прежде всего, человек высоких нравов; его миссия на земле - установить честность и правдивость, развеять плохие образы и обычаи, установить законы, ведущие к добру, и призвать людей к Богу. Чтобы достичь этого уровня, нужно осознавать себя. Ведь, по мнению русского философа, человек, не понимающий себя, умирает, ничего не осознавая. Это означает, что человек шаг за шагом достигает совершенства, путём воспитания религиозности и чистоты в мирской жизни [12]. Как мыслитель религиозного формата Лосев не просто рассуждает о цивилизации и места в ней идеального человека. Его идеи чётко направлены на развитие отечественной культуры, на сознание русского православного человека и систему социальных и духовных ценностей. Приоритетными для него являются именно ценности православной культуры, сформировавшими менталитет русского народа.

В сознании русского человека, по Лосеву, особое значение имеют элементы символического характера, основанные на христианской обрядности. Любой ритуал - это выполнение того или иного обряда, поэтому в православии наиболее значима символика обрядности. Она призвана активно влиять на чувства верующих людей для обеспечения поддержания и углубления их религиозности. И здесь важнейшую роль играют таинства. Под таинствами в христианстве принято понимать обрядовые действия, в которых «под видимым образом сообщается верующим невидимая Благодать Божия» [13; С.10]. Их семь таинств: крещение, миропомазание, причащение, исповедь, брак, соборование. Для профессиональных служителей русской православной церкви это и еще таинство священства.

Вместе с православием на русскую почву пришла концепция соборности. Соборность - органичная составляющая русской духовной культуры. Ключевыми ее символами являлись не только собор как храм в прямом смысле данного слова, но и этническое собрание, вече, сход, то есть начала самоуправления. Дух этноса отражается в его культуре. Соборность, с точки зрения большинства выдающихся отечественных мыслителей, основа русской духовной культуры и русского национального характера. С течением времени создавалась своеобразная философия соборности, базирующаяся на национальной почве русского народа.
На данный момент определение «соборности» применяется в связи с духовным кризисом, потребовавшим восстановления в нашем обществе классических духовных ориентиров. Соборность является единственной альтернативой западной системы ценностей (мультикультуризм, гендер и др.). Последние чужды не только традициям русского этноса, но и его характеру, мировосприятию и миропониманию. По сути, соборность является ничем иным, как специфическим явлением многовекового развития русской духовной культуры, противоположным западноевропейскому рационализму и индивидуализму. С течением времени идеал соборности стал представлять собой основу нравственного сознания русского этноса. Он достаточно востребован в наши дни как этический базис социокультурной жизни российского общества, а теоретически он был осмыслен в философии славянофилов.

В философской литературе термин «соборность» активно использовался ранними славянофилами А.С. Хомяковым и И.В. Киреевским. Само по себе славянофильство выступает преимущественно философией соборности, поскольку всесторонне раскрывает данное понятие. В рамках славянофильства также установлены 2 ключевых критерия соборности:

- внутренний (религиозно-этический);

- внешний (социально-политический).

Наибольшую важность для славянофильства представляет религиозно-этический критерий соборности. С точки зрения Хомякова, церковный собор отражает концепцию единства во множестве [14]. По мнению философа, это проявляется не только в видимом объединении людей в том или ином отдельно взятом месте, но и в едином смысле имеющейся возможности подобного рода объединения. Соборность для славянофилов представляет собой церковную общность этноса, объединенного одной верой; православные ценности, которые обеспечивают духовное единство личности. Соборность, по их мнению, это ничто иное как единство многих людей, сформировавшееся на базе единой их веры в Бога, сына Божьего Иисуса Христа и в Правду Божию. Соборность является не количественным, а качественным термином. В соответствии со славянофилами, категория соборности обладает и внешним - социально-политическим критерием. При этом последний предполагает оцерковление социальной жизни, возрождение элементов первой христианско-апостольской церкви. Одним из основных социальных аналогов соборности принято считать общину, которая предохраняет от реализации человеческого эгоизма в его поступках; органическое государство, сформированное непосредственно на духовных началах $[15 ;$ С.22-23].

Уважение русского человека друг к другу, православная соборность дадут возможность нашему этносу 
снова стать одним целым, сильным в духовном и физическом плане, не поддаваться экстремизму и ксенофобии. Русская культура была и есть одним из ключевых признаков, неотъемлемой составляющей русского этноса.

Святая соборность по философии славянофилов призывает людей к сбережению единства величайшей во всем мире русской культуры. Значимость осмысления концепции соборности как основы отечественной духовной культуры состоит и в том, что эта идея может быть исследована на 2-х уровнях:

- соборность мистическая;

- соборность историческая.

Между отмеченными уровнями отсутствуют границы, поскольку они очень тесно связаны и взаимопроникающи. По мнению современного историка русской философии Л.Е. Шапошникова, внешняя, количественная, и внутренняя, качественная, стороны соборности не могут существовать отчужденно друг от друга, поскольку они тесно связаны между собой. Он указывает на то, что эта сущность «дана на века», а явление при этом носит только лишь исторический характер [16; С.48].

Под мистической соборностью Шапошников понимает абсолютный идеал. В реальной жизни общество и современный индивид крайне далеки от этого идеала. Однако при этом исследователь указывает на наличие стремления народа к такому идеалу. В связи с этим соборность приобретает форму идеала. Именно в этом и заключается его ключевая нравственная значимость для человечества символическая форма движения к единству всех людей вне религий и этнических рамок.

Русскому этносу оказались очень близкими по смыслу ряд христианских идеалов и принципов, изначально носивших в себе концепцию соборности. К примеру, изначально Христианство воспринималось русским человеком в качестве религии, обращенной к миру, к людям. Данный факт отмечается С.А. Левицким в одном из его трудов. Автор считает, что если всмотреться в киевский период, то можно заметить чистоту восприятия христианства предками нашего этноса. Благая весть в те времена воспринималась людьми гармонично и светло. Наши предки вдохновлялись стремлением к деятельности христианской любви. Не зря один из первых отечественных святых - Феодосий Печерский - не был затворной личностью [17; С.13]. Русской душе оказался более понятным путь спасения С-МИРом, чем путь спасения в изоляции от мира. Благодаря православной духовности, религии удалось сыграть в отечественной философии роль ключевого смыслообразующего элемента. Православие стало одним из важнейших источников своеобразия, оригинальности, всего самого сокровенного и глубокого в русской религиозной философии. Оно стало базой отечественной философии соборности.

\section{Зак^ючение}

Подводя итог, укажем, что в результате анализа таких понятий как «базовые ценности», «духовная культура», «духовность», «русская духовная культура» и «соборность»:

1. Духовные ценности для русского этноса выступают наиболее значимыми социокультурными ценностями, также как философия и социокультурная практика соборности. Теоретически осмысленный феномен соборности в философии славянофильства в наше время приобретает важность и требует преодоления системного кризиса отечественного общества.

2. В XXI веке России необходимо было совершить выбор между исторически сформировавшейся национальной культурой и её ключевыми традиционными ценностями, и ценностями западного образа жизни. Воспитание молодёжи в рамках отечественной системы духовных ценностей стало сегодня одной из насущных задач молодёжной политики российского государства.

3. Русская культура серебряного века стала толчком к появлению интереса к философии символизма как отражению поисков деятелей художественной культуры прошлых веков. Отечественные символисты, интерпретируя культуру как «духовно-общественное бытие», рассматривали духовность в качестве главного символа отечественной культуры, понимая под нею приверженность к православной вере, соборности и началам социокультурной самоорганизации.

\section{ЛИТЕРАТУРА}

1. Аристотель. Никомахова этика / Соч. в 4-х тт. Т.4. - М.: Мысль, 1983. - С.62

2. Риккерт Г. Философия жизни. Киев: «Ника-Центр», «Вист-С», 1998.- 505 с.

3. Абушенко В.Л. Аксиология / Новейший философский словарь: 3-е изд., исправл.- Минск: Книжный Дом,2003. - С.25

4. https://www.psychologos.ru/

5. Сагатовский В.Н. Философия развивающейся гармонии (философские основы мировоззрения) в 3-х частях. Ч.3: Антропология. СПб. 1999. С. 131-140

6. Лосев А.Ф. Философия. Мифология. Культура. М.,1991. С.509.

7. Сартр Ж.П. Бытие и ничто. М.: Издательство АСТ. 2020. - 1072 с. 
8. Сартр Ж.П. Экзистенциализм - это гуманизм. В кн.: Сумерки богов. М.: «Политиздат», 1989. с. 319-344.

9. Камю А. Посторонний, Чума, Падение. Рассказы и эссе М.: Радуга, 1988. - 464 с.

10. Камю А. Бунтующий человек; Философия, политика, искусство. (Общая редакция, составитель и предисловие кандидат философских наук А.М. Руткевича). М.: Политиздат, 1990. - 415 с.

11. Василенкова А.А. Патриотическое воспитание молодёжи на традициях войны и мира // Ключъ: Выпуск 16. - Матер. Нац. Научно-практ. Конф. С междунар. Участием «Значение Победы в Великой Отечественной войне для настоящего и будущего России». - СПб.; СПбГАУ, Сухум, АГУ, 2021.- С. 89-91

12. Бердяев Н.А. Дух и реальность: основы боговечности духовности / Философия свободного духа. - М.Ж Республика, 1994. - С. 364-461

13. https://docviewer.yandex.ru

14. Бердяев Н.А. Самопознание. -М.: Книга, 1991. - 445 с.

15. Лосев А.Ф. Очерки античного символизма и мифологии. - М.: Изд-во: Академический проспект, 2013. - 848 с.

16. Лосев А.Ф. Проблема символа и реалистическое искусство. - М: Искусство, 1995. - 320 с.

17. Осипов И.Д. Философия политики и права в России: монография. - СПб.: Изд-во С.-Петерб. Гос. ун-та, 2014. - 262 с.

18. Белкин А.И. Православие как разновидность христианства. Саранск, 1998. - С.10.

19. Хомяков А.С. Письмо к редактору «L'Union Chrètienne» о значении слов: «Кафолический» и «Соборный» по поводу речи иезуита отца Гагарина. Полн. Собр. Соч. М., 1911. Т.2.

20. Арефьев М.А., Давыденкова А.Г., Осипов И.Д. Русская культурология. Ч.І. Культура российского самоуправления. СПб., 2003. С.22-23.

21. Шапошников Л.Е. Проблема богословского творчества в наследии С.Н. Булгакова / Русское православие: Вехи истории. Ниж. Новгород, 1998. - С.48.

22. Левицкий С.А. Очерки по истории русской философии. М.,1996. - С.13.

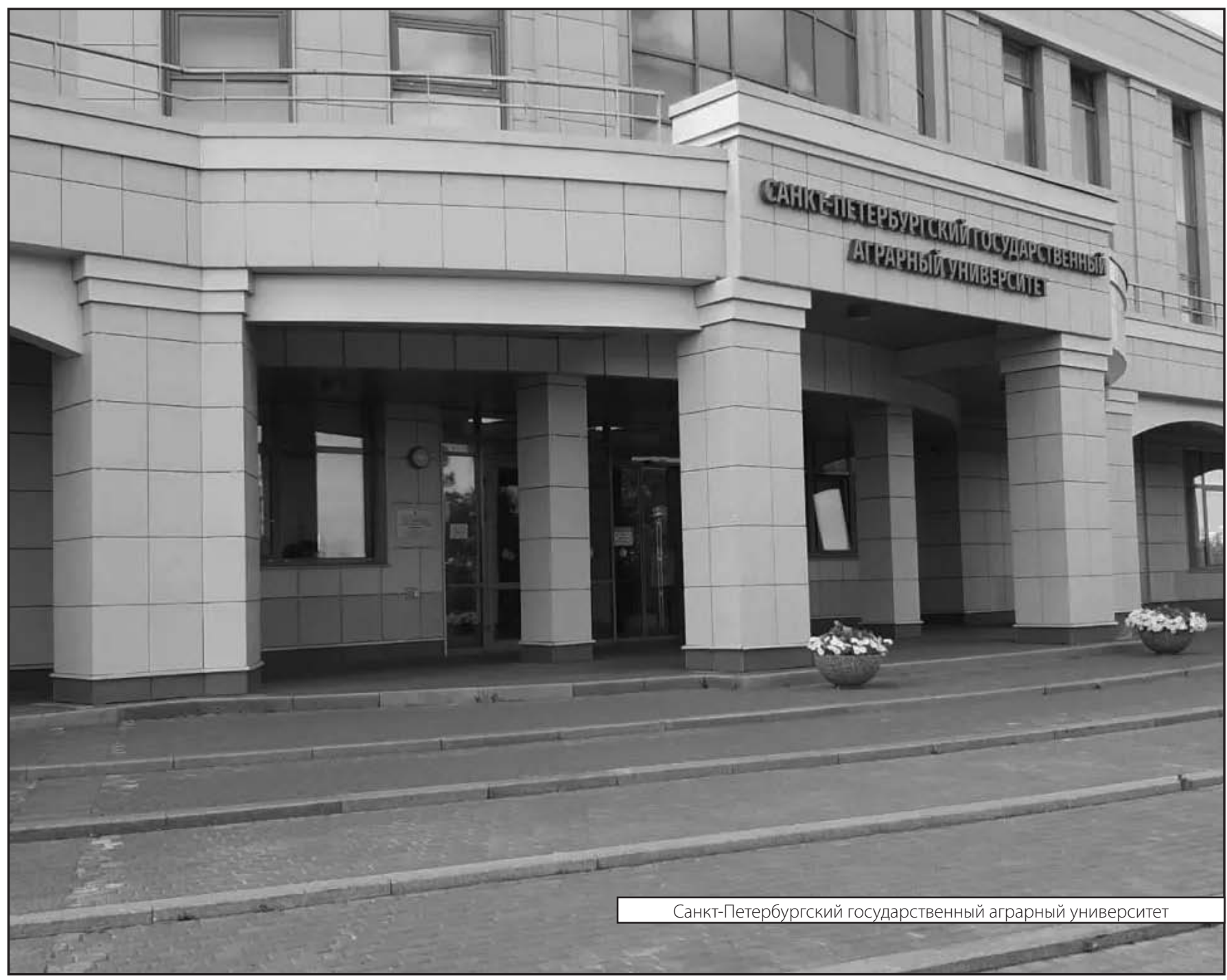

